\title{
Carbon nanotube@silicon carbide coaxial heterojunction nanotubes as metal-free photocatalysts for enhanced hydrogen evolution
}

\author{
Xunfu Zhou, Qiongzhi Gao, Siyuan Yang *, Yueping Fang \# \\ College of Materials and Energy, South China Agricultural University, Guangzhou 510642, Guangdong, China
}

A R T I C L E I N F O

\section{Article history:}

Received 29 April 2019

Accepted 3 June 2019

Published 5 January 2020

\section{Keywords:}

Silicon carbide

Coaxial core-shell nanotubes

Nanoheterostructures

Charge separation

Hydrogen evolution

\begin{abstract}
A B S T R A C T
Considerable research efforts have been devoted to developing novel photocatalysts with increased performances by hybridizing inorganic nanomaterials with carbon nanotubes. In this work, one-dimensional coaxial core-shell carbon nanotubes@SiC nanotubes were successfully synthesized via in situ growth of $\mathrm{SiC}$ coatings on carbon nanotubes by a vapor-solid reaction between silicon vapor and carbon nanotubes. High-resolution transmission electron microscope images show that $\mathrm{SiC}$ and carbon nanotubes link to form a robust heterojunction with intrinsic atomic contact, which results in efficient separation of the photogenerated electron-hole pairs on SiC and electron transfer from $\mathrm{SiC}$ to carbon nanotubes. Compared with those of similar materials such as pure SiC nanocrystals and SiC nanotubes, the metal-free carbon nanotubes@SiC exhibits an enhanced photocatalytic activity for hydrogen evolution, which is attributed to the enhanced light absorption and the efficient interfacial charge transfer/separation brought about by their one-dimensional coaxial nanoheterostructures. Moreover, the photocatalytic stability of the metal-free carbon nanotubes@SiC was tested for over 20 h without any obvious decay.
\end{abstract}

(C) 2020, Dalian Institute of Chemical Physics, Chinese Academy of Sciences. Published by Elsevier B.V. All rights reserved.

\section{Introduction}

There is a growing need to develop sustainable "green" energy sources for replacing the classical fossil fuels for protecting our natural environment and alleviating the problem of global energy crisis [1]. Hydrogen $\left(\mathrm{H}_{2}\right)$, with its high energy capacity and environmental friendliness, is a source of clean energy that is generated from renewable sources such as solar $[2,3]$. Notably, photocatalytic (PC) $\mathrm{H}_{2}$ generation through water splitting has received tremendous attention in recent decades [4]. However, many conventional PC materials (namely, metal sulphides and (oxy) nitrides such as $\mathrm{TiO}_{2}, \mathrm{Zn}_{0.8} \mathrm{Cd}_{0.2} \mathrm{~S}, \mathrm{Cu}_{2} \mathrm{O}$, $\mathrm{WO}_{3}, \mathrm{Ga}_{2} \mathrm{O}_{3}, \mathrm{~g}-\mathrm{C}_{3} \mathrm{~N}_{4}, \mathrm{ZnIn}_{2} \mathrm{~S}_{4}, \mathrm{CdS}$, and $\mathrm{ZnS}$ ) cannot satisfy the requirements of low toxicity, low cost, high stability, and re- markable PC activity for practical applications [5-13]. In this context, the development of new photocatalysts, micro/nano structure engineering, and surface/interface engineering of heterogeneous semiconductors by optimizing suitable material combinations has been identified as a viable approach to improving the $\mathrm{H}_{2}$ production rates of functional compounds [14-21]. Hybridization of semiconductor photocatalysts with carbon nanotubes (CNTs) affords a powerful strategy of designing advanced PC materials [22,23]. Particularly, incorporation of CNTs into heterogeneous photocatalysts can offer potential advantages in terms of improved PC performances. On one hand, the one-dimensional (1-D) conductive channels of CNTs provide pathways for rapid electron transfer, which decrease the recombination of the photoinduced electron-hole

\footnotetext{
* Corresponding author. E-mail: siyuan_yang@scau.edu.cn

\# Corresponding author. E-mail: ypfang@scau.edu.cn

This research was supported by the National Natural Science Foundation of China (21673083, 21802046). The authors thank the Guangdong Provincial Science and Technology Project (2017A030313090, 2014A030310427).

DOI: S1872-2067(19)63421-2 | http://www.sciencedirect.com/science/journal/18722067 | Chin. J. Catal., Vol. 41, No. 1, January 2020
} 
pairs [24]. On the other hand, CNTs with an elaborated 1-D morphology could serve as good templates to induce the growth of semiconductors with 1-D nanostructures [25,26] and core-shell architectures $[27,28]$ that display enhanced charge transport and improved PC efficiency. Indeed, previous studies focusing on the coupling of CNTs and $\mathrm{TiO}_{2}$ have documented prominent improvements in the PC performance of the hybrid over those of the individual constituents [29-31]. For example, the activity of core-shell CNTs/ $\mathrm{TiO}_{2}$ nanocomposites for the PC degradation of methylene blue increased 2-3 times upon hybridization with $\sim 16 \mathrm{wt} \%$ of CNTs [32]. This considerable enhancement is attributed to the uniform coating of nanocrystal $\mathrm{TiO}_{2}$ onto CNTs to form a core-shell structure with high-quality interfacial contacts between $\mathrm{CNTs}$ and $\mathrm{TiO}_{2}$, which largely facilitate the separation of the electron-hole pairs and lead to a better PC performance. Furthermore, micro/nanocomposites that combine CNTs with other commonly used PC materials such as $\mathrm{ZnO}$ [33], ZnS [34], CdS [35], $\mathrm{WO}_{3}$ [36], and $\mathrm{C}_{3} \mathrm{~N}_{4}$ [37], have also been demonstrated as hybrids that reveal enhanced PC performances through similar mechanisms.

It is well known that $\beta$-SiC (cubic phase silicon carbide) is a potential photocatalyst that exhibits an appropriate band gap $\left(E_{\mathrm{g}}=2.4 \mathrm{eV}, E_{\mathrm{CB}}=-0.9 \mathrm{~V}\right.$ vs. $\mathrm{NHE}$ at room temperature) for PC $\mathrm{H}_{2}$ generation [38]. Until now, there has been limited research on SiC photocatalysts. The main reason for this is the rapid recombination of the photoinduced electron-hole pairs in $\mathrm{SiC}$ photocatalysts $[39,40]$. Therefore, various engineering strategies, including the formation of unique $\mathrm{SiC}$ nanostructures (e.g., quantum dots [41], nanoparticles [42], nanowires [43], and hollow spheres[44]), construction of heterostructures (e.g.,

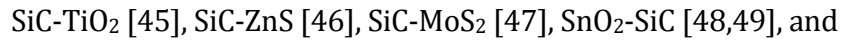
SiC-CdS [50]), hybridization of SiC with metal co-catalysts (e.g., SiC-Pt [43], $\mathrm{SiC}^{-\mathrm{IrO}_{2}}$ [51]), and nanocarbon materials (e.g., SiC-graphene [52,53]), have been employed to promote the performance and durability of SiC photocatalysts since the initial research on water splitting in 1990 [54]. Further investigations show that the SiC-graphene nanoheterojunction with intimate interfacial contacts between $\mathrm{SiC}$ and graphene exhibits enhanced photoactivities for water splitting owing to the improved charge separation resulting from the formation of Schottky-junction interfaces [55]. In our previous studies, we have demonstrated that the well-designed CNTs/SiC nanowire nanoheterostructures exhibit enhanced PC activity, compared with that of individual $\mathrm{SiC}$ nanowires [56]. Owing to vapor-liquid-solid catalytic growth, the CNTs/SiC nanoheterostructures are composed of straight $\mathrm{SiC}$ nanowires and crooked CNTs. In the present work, we demonstrate that CNTs can be uniformly covered with $\mathrm{SiC}$ nanoshells to form coaxial CNT@SiC core-shell nanotubes (C@SiCNTs) via an in situ vapor-solid reaction between silicon vapor and CNTs. Owing to the rational coaxial core-shell structure with tight Schottky junctions between CNTs and SiC, both the interfacial coupling and charge separation of C@SiCNT nanoheterostructures can be greatly improved. As a result, the metal-free C@SiCNTs exhibits significantly improved performance in PC generation of $\mathrm{H}_{2}$ from pure water. The enhanced mechanisms of $\mathrm{PC} \mathrm{H}_{2}$ generation over C@SiCNTs are discussed in detail.

\section{Experimental}

\subsection{Material synthesis}

Sodium sulphide, hydrofluoric acid, sulfuric acid, and nitric acid were supplied by Sinopharm Chemical Reagent Co., Ltd. Micro-grade silicon powder (40-200 mesh) was provided by Aladdin. Multi-walled carbon nanotubes (CNTs; length, 5-15 $\mu \mathrm{m}$; specific surface area, 40-70 $\mathrm{m}^{2} \mathrm{~g}^{-1}$; diameter, $60-100 \mathrm{~nm}$; purity, >97\%) were purchased from Shenzhen Nanotech Port Co., Ltd.

In a typical process, the CNTs were first purified with a mixed concentrated $\mathrm{H}_{2} \mathrm{SO}_{4} / \mathrm{HNO}_{3}$ solution (volume ratio, 3:1) at room temperature. Then, $0.6 \mathrm{~g}$ of the acid-purified CNTs and excess silicon powder were mixed and placed inside a horizontal furnace. Subsequently, the furnace was heated to $1320{ }^{\circ} \mathrm{C}$. Simultaneously, argon gas was made to flow at $250 \mathrm{~mL} / \mathrm{min}$ at one end of the tubular furnace. The temperature was kept at $1320{ }^{\circ} \mathrm{C}$ for $2 \mathrm{~h}$. Subsequently, the sample was cooled and washed with a mixed $\mathrm{HF} / \mathrm{HNO}_{3}$ diluted (aqueous) solution. Finally, the obtained C@SiCNT nanoheterostructures sample was filtered and dried for further use.

The SiCNTs were obtained by increasing the reaction time to $4 \mathrm{~h}$ and keeping the other parameters unchanged, so that the carbon nanotubes were almost completely consumed.

Reference $\mathrm{SiC}$ nanocrystals were synthesized by annealing the C@SiCNTs at $750{ }^{\circ} \mathrm{C}$ in air for $2 \mathrm{~h}$, which consumed the CNTs by oxidation.

\subsection{Characterization}

The crystalline structures of the specimens were characterized by X-ray diffraction (XRD) (Rigaku, Cu $K \alpha$ radiation, $\lambda=$ $0.15418 \mathrm{~nm}$ ) in the scanning range $10^{\circ}-80^{\circ}$. The $\mathrm{N}_{2}$ adsorption-desorption isotherm was determined at $77 \mathrm{~K}$ by using a surface area analyzer (Micromeritics Co., Gemini-2360). Then, Brunauer-Emmett-Teller (BET) method was used to determine the specific surface areas. X-ray photoelectron spectroscopy (XPS) was carried out with a VGESCALAB250 surface analysis system. The morphologies, structures, and elemental distributions of the products were examined by a scanning electron microscopy (SEM) (FEI Quanta 200 FEG) and a high-resolution transmission electron microscopy (TEM) (FEI Glacios Cryo-TEM, acceleration voltage: $200 \mathrm{kV}$ ). The carbon content was analyzed by a thermogravimetric analyzer under air flow. The UV-vis diffuse reflectance spectra were recorded by using a spectrophotometer (Shimadzu, model 2501 PC). The photoluminescence (PL) spectra were obtained with the help of a PerkinElmer fluorescence spectrophotometer at the excitation wavelength of $290 \mathrm{~nm}$. The transient PL spectra were recorded by a fluorescence lifetime spectrophotometer (Edinburgh Instruments, UK FLS920) at the excitation wavelength of $290 \mathrm{~nm}$.

\subsection{Photoelectrochemical measurements}

$80 \mu \mathrm{L}$ of $0.5 \mathrm{wt} \%$ Nafion solution and $10 \mathrm{mg}$ of the photocatalyst powders were added to $2.0 \mathrm{ml}$ ethanol, and then, ul- 
trasonic treatment was performed for 30 min to obtain a suspension. Then, $400 \mu \mathrm{L}$ of the suspension was dropped onto a 3 $\times 2 \mathrm{~cm}^{2}$ FTO glass substrate. Subsequently, the FTO glass substrate was dried and annealed at $150{ }^{\circ} \mathrm{C}$ for $1 \mathrm{~h}$ in argon flow. The transient photocurrent properties of the sample at $0.2 \mathrm{~V}$ bias were measured by an electrochemical analyzer by using a three-electrode system. A platinum electrode and the $\mathrm{Ag} / \mathrm{AgCl}$ electrode (with saturated $\mathrm{KCl}$ ) were used as the counter electrode and reference electrode, respectively. The light source was a $300 \mathrm{~W}$ Xe lamp (with AM 1.5 simulated sunlight cut-off filter). The electrolyte was $0.5 \mathrm{~mol} / \mathrm{L} \mathrm{Na}_{2} \mathrm{SO}_{4}$ solution. The Mott-Schottky plots were recorded at an ac amplitude of $5 \mathrm{mV}$ with a frequency of $1000 \mathrm{~Hz}$ under dark condition. The electrochemical impedance spectra of the samples were obtained under the condition that the ac amplitude was $5 \mathrm{mV}$ and the frequency range $0.01-10^{5} \mathrm{~Hz}$.

Electrocatalytic $\mathrm{H}_{2}$ evolution was also carried out by using the three-electrode cell. The polarization curves were recorded at $5 \mathrm{mV} \mathrm{s}^{-1}$ scan rate. To convert the measured potentials (versus $\mathrm{Ag} / \mathrm{AgCl}$ ) to the RHE scale, Eq. (1) was employed.

$$
E_{\mathrm{RHE}}=E_{\mathrm{AgCl}}+0.059 \mathrm{pH}+E_{\mathrm{AgCl}}^{0}\left(E_{\mathrm{AgCl}}^{0}=0.197 \mathrm{~V}\right)
$$

\subsection{PC water splitting}

A $300 \mathrm{~W}$ Xe lamp equipped with a simulated sunlight cut-off filter (AM 1.5) was used as the light source. The $\mathrm{PC} \mathrm{H}_{2}$ evolution was observed in a $200 \mathrm{~mL}$ Pyrex flask (three-necked, flat-bottom) at room temperature and pressure. The flask was sealed with a silicon rubber ring. The distance from the reactor to the light source was $20 \mathrm{~cm}$. In a typical PC $\mathrm{H}_{2}$ evolution experiment, $15 \mathrm{mg}$ of the photocatalyst was added to $100 \mathrm{~mL}$ of aqueous $\mathrm{Na}_{2} \mathrm{~S}(0.1 \mathrm{~mol} / \mathrm{L})$ solution, then ultrasonic treatment was carried out for $30 \mathrm{~min}$ to form a suspension in the flask reactor. Nitrogen was bubbled into the suspension for $30 \mathrm{~min}$ to remove oxygen. $400 \mu \mathrm{L}$ of the gas was extracted and analyzed by using a gas chromatograph (GC-7900, TCD, argon atmosphere) after $1 \mathrm{~h}$ of irradiation.

A cyclic experiment was carried out to determine the PC stability of C@SiCNTs. After 5 h of irradiation, the $\mathrm{H}_{2}$ produced was substituted by $\mathrm{N}_{2}$, which was followed by another $5 \mathrm{~h}$ of irradiation. According to the practical $\mathrm{H}_{2}$ generation under 420 $\mathrm{nm}$ illumination, the apparent quantum efficiencies (AQEs) were calculated to determine the solar energy conversion abilities of C@SiCNTs, SiCNTs, and the reference SiC by using the following equation [57].

$$
\mathrm{AQE}=\frac{2 \times \mathrm{N}_{\mathrm{H}_{2}}\left(\mathrm{~S}^{-1} \cdot \mathrm{cm}^{-2}\right)}{\mathrm{P}_{\lambda}\left(\mathrm{mW} \cdot \mathrm{cm}^{-2}\right) \div \mathrm{E}_{\lambda}\left(\mathrm{mW} \cdot \mathrm{s}^{-1}\right)} \times 100 \%
$$

where $\mathrm{N}_{\mathrm{H} 2}$ is the number of molecules of $\mathrm{H}_{2}$ produced, $\lambda$ is the wavelength of the irradiated monochromatic light, $E_{\lambda}$ and $P_{\lambda}$ are the average photon energy and the light intensity per unit area corresponding to $\lambda$, respectively.

\section{Results and discussion}

\subsection{Structure and composition of the photocatalysts}

The fabrication of C@SiCNTs is illustrated in Scheme 1. Sili-

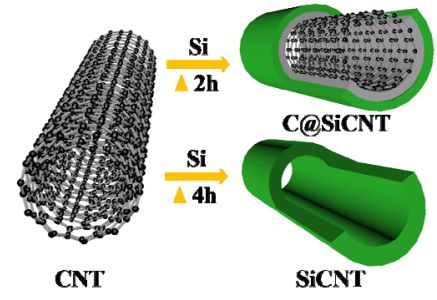

Scheme 1. Fabrication of C@SiCNT hybrids and SiCNTs.

con powder and CNTs were grinded together and placed inside a horizontal furnace. Then, the furnace was heated to $1320^{\circ} \mathrm{C}$ in argon atmosphere because the sublimation temperature and melting point of the silicon powder are 1127 and $1420^{\circ} \mathrm{C}$, respectively. The formation of SiC shells on the CNTs involved a vapor-solid reaction between the solid CNTs and the silicon vapor (Eq. (3)) [55]:

$$
\mathrm{Si}_{(\mathrm{g})}+\mathrm{C}_{(\mathrm{s})}=\mathrm{SiC}_{(\mathrm{s})}
$$

After the in situ vapor-solid reaction between CNTs and silicon vapor for $2 \mathrm{~h}$, C@SiCNTs were obtained. When the vapor-solid reaction time increased to $4 \mathrm{~h}$, almost all the CNTs were consumed completely by the silicon vapor and converted to $\mathrm{SiC}$, then, SiCNTs were obtained. If the furnace was heated to $1500{ }^{\circ} \mathrm{C}$, micron $\mathrm{SiC}$ crystal of large particles was obtained. Because the synthesis temperature is higher than the melting point of silicon, the reaction between silicon and carbon changes from a vapor-solid reaction to a liquid-solid reaction. This phenomenon was observed and discussed in detail in our previous report [48]. Therefore, C@SiCNTs can only be formed with the right combination of reaction conditions. The reference $\mathrm{SiC}$ was obtained by annealing the C@SiCNTs at $750{ }^{\circ} \mathrm{C}$ for $4 \mathrm{~h}$ in air. The obtained specimens were characterized by XRD, and the patterns are presented in Fig. 1(a). It is observed that the original CNTs exhibit hexagonal structure, and the space group is $\mathrm{P} 6_{3} / \mathrm{mmc}$ (JCPDS PDF no. 41-1487). The diffraction peak angles of $26.2^{\circ}, 42.8^{\circ}$, and $44.6^{\circ}$ correspond to the (002), (100), and (101) lattice planes of CNTs, respectively. After the reaction with silicon vapor for $2 \mathrm{~h}$, the diffraction peaks at $42.8^{\circ}$ and $44.6^{\circ}$ disappeared, due to the formation of the SiC coating on the CNTs. On the other hand, diffraction peaks at $35.4^{\circ}$, $41.2^{\circ}, 59.8^{\circ}, 71.6^{\circ}$, and $75.4^{\circ}$, corresponding to the (111), (200), (220), (311), and (222) lattice planes of $\beta$-SiC (JCPDS PDF no. 29-1129), respectively, can be found in the C@SiCNTs. Further, a diffraction peak at $26.2^{\circ}$, indexed to the (002) reflections of CNTs, can also be observed in the XRD pattern of C@SiCNTs. The low intensity diffraction peak at $33.6^{\circ}$ corresponds to the stacking faults of $\mathrm{SiC}$. It is confirmed that the as-prepared C@SiCNTs are composed of CNTs and $\beta$-SiC [58]. Upon increasing the reaction time to $4 \mathrm{~h}$, CNTs were almost completely transformed to $\beta$-SiC in situ, so that only the diffraction peaks of $\beta$-SiC are observed in the XRD pattern of SiCNTs. Similarly, the reference $\mathrm{SiC}$ nanocrystals are composed of pure $\beta$-SiC.

The SiC contents of the as-prepared samples were determined by thermogravimetric analysis (Fig. 1(b)). The mass fraction of SiC in C@SiCNTs is about 70.5 wt\%. It is found that SiCNTs and $\mathrm{SiC}$ are stable (up to $900{ }^{\circ} \mathrm{C}$ in air), since no remarkable weight losses $(2.0 \%$ for SiCNTs and $1.5 \%$ for the ref- 
(a)
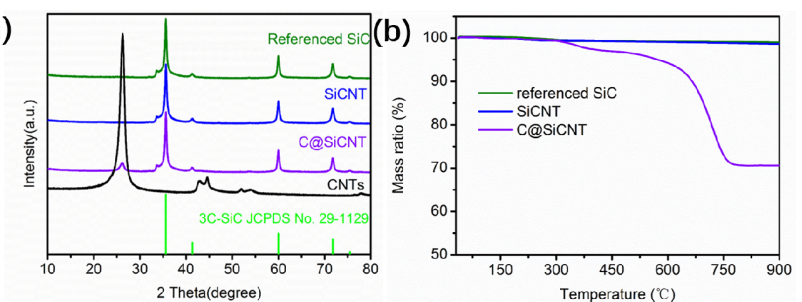

(c)
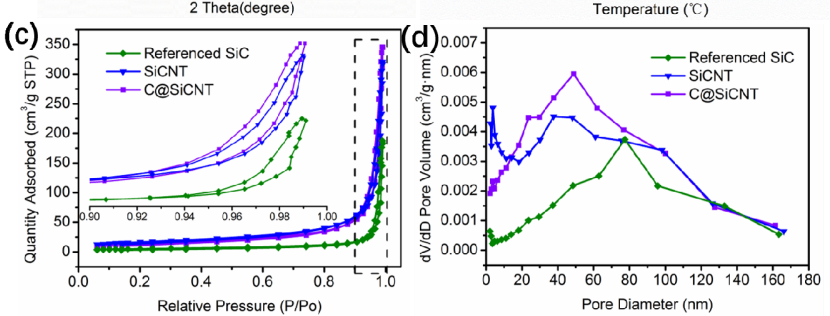

Fig. 1. Powder XRD patterns (a), TGA profiles (b), $\mathrm{N}_{2}$ adsorption and desorption isotherms (c) and the corresponding pore size distribution curves (d) of as prepared samples.

erence $\mathrm{SiC}$ ) are observed in this temperature range.

The textural properties of the C@SiCNTs, SiCNTs, and reference $\mathrm{SiC}$ samples are revealed in Fig. 1(c); obviously, all the specimens exhibit type III adsorption-desorption isotherms with type H3 hysteretic loops, which indicate the presence of mesopores connected by macropores in the samples [59]. Moreover, the isotherms reveal mass absorption in the high relative pressure zone (inset in Fig. 1(c)), which indicates the presence of large mesopores, which are observed in Fig. 1(d). As presented in Table 1, the BET surface areas of C@SiCNTs $\left(62.57 \mathrm{~m}^{2} \mathrm{~g}^{-1}\right)$ and SiCNTs (55.66 $\left.\mathrm{m}^{2} \mathrm{~g}^{-1}\right)$ are about 3.4 and 3.0 times that of the reference $\mathrm{SiC}\left(18.56 \mathrm{~m}^{2} \mathrm{~g}^{-1}\right)$, respectively, which further suggest that C@SiCNTs and SiCNTs are topologically transformed from acid-purified CNTs (specific surface area, $40-70 \mathrm{~m}^{2} \mathrm{~g}^{-1}$; diameter, $60-100 \mathrm{~nm}$ ). More interestingly, the mean pore diameters of C@SiCNTs (39.52 nm) and SiCNTs (32.94 nm) are smaller than that of CNTs (60-100 nm), which maybe correspond to the inner diameter of the CNTs. On the contrary, the mean pore diameter of the reference SiC $(60.61$ $\mathrm{nm}$ ) is greater than that of the CNTs, which is because of the presence of slit-like pores that originated from the aggregation of particles. Such a nanostructure can significantly enhance the PC activity, because it provides open pores for guest molecules and also improves the light absorption through multiple scattering effects [60].

To gain further insight into the surface compositions of the catalysts, XPS was employed. The high-resolution Si $2 p$ spectrum (Fig. 2(a)) of C@SiCNTs can be deconvoluted into two peaks corresponding to the $\mathrm{Si}-\mathrm{C}$ bonds $(101.18 \mathrm{eV})$ of CNTs and $\mathrm{Si}-\mathrm{O}$ bonds $(102.03 \mathrm{eV})$ of $\mathrm{SiO}_{x}$. The deconvoluted $\mathrm{C} 1 s$ spectrum (Fig. 2(b)) of the C@SiCNTs shows two peaks at the bind-

Table 1

Textural properties of C@SiCNTs, SiCNTs, and the reference SiC.

\begin{tabular}{lccc}
\hline Photocatalyst & $\begin{array}{c}\text { BET surface area } \\
\left(\mathrm{m}^{2} \mathrm{~g}^{-1}\right)\end{array}$ & $\begin{array}{c}\text { Mean pore } \\
\text { diameter }(\mathrm{nm})\end{array}$ & $\begin{array}{c}\text { Pore volume } \\
\left(\mathrm{cm}^{3} \mathrm{~g}^{-1}\right)\end{array}$ \\
\hline C@SiCNTs & 62.57 & 39.52 & 0.37 \\
SiCNTs & 55.66 & 32.94 & 0.34 \\
Reference SiC & 18.56 & 60.61 & 0.16 \\
\hline
\end{tabular}
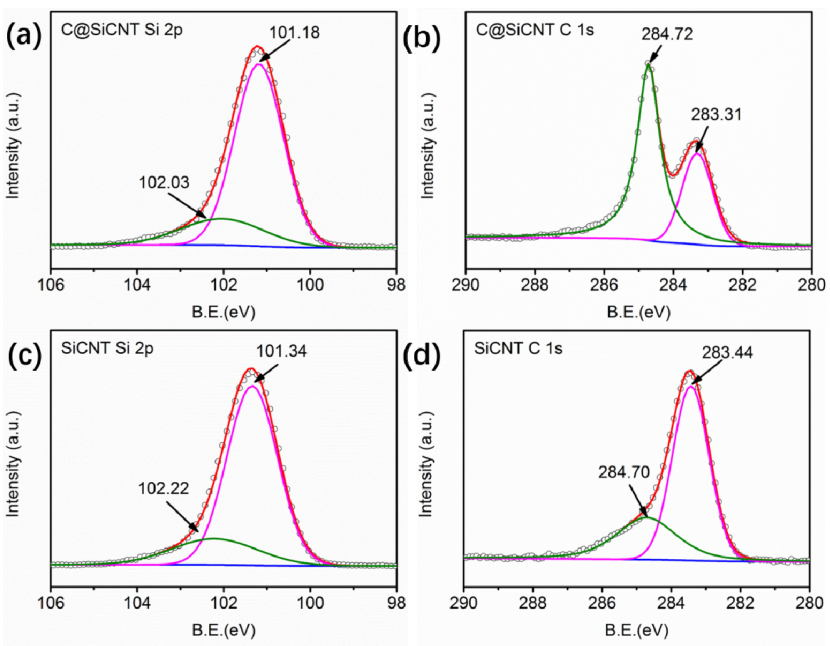

Fig. 2. Si $2 p$ and C $1 s$ XPS spectra of C@SiCNTs (a, b) and SiCNTs (c, d).

ing energies of $284.72 \mathrm{eV}$ and $283.31 \mathrm{eV}$, which are indexed to the $\mathrm{C}-\mathrm{C}$ bonds of CNTs and the $\mathrm{C}-\mathrm{Si}$ bonds of $\mathrm{SiC}$, respectively [61]. In addition, the deconvoluted Si $2 p$ spectrum (Fig. 2(c)) of the SiCNTs reveals two peaks at 101.34 and $102.22 \mathrm{eV}$, which correspond to the $\mathrm{Si}-\mathrm{C}$ bonds of $\mathrm{SiC}$ and the $\mathrm{Si}-\mathrm{O}$ bonds of $\mathrm{SiO}_{x}$, respectively. The deconvoluted $\mathrm{C} 1 s$ spectrum (Fig. 2(d)) of the SiCNTs displays two peaks at the binding energies of 284.70 and $283.44 \mathrm{eV}$, which are indexed to the $\mathrm{C}-\mathrm{C}$ bonds of CNTs and the $\mathrm{C}-\mathrm{Si}$ bonds of $\mathrm{SiC}$, respectively. Notably, the peak intensity of the $\mathrm{C}-\mathrm{C}$ bonds of SiCNTs is much lower than that of the $\mathrm{C}-\mathrm{C}$ bonds of C@SiCNTs, which indicates a low content of carbon in the SiCNTs. The atomic fractions of silicon, carbon, and oxygen in the C@SiCNTs are 29.35\%, 65.62\%, and 5.03\%, respectively. Similarly, the atomic fractions of silicon, carbon, and oxygen in the SiCNTs are $45.54 \%, 49.01 \%$, and 5.45\%, respectively. Calculated from the atomic fractions, the mass fraction of $\mathrm{SiC}$ in the C@SiCNTs is about $72.5 \mathrm{wt} \%$, which is close to the results of thermogravimetric analysis (Fig. 1(b)). In addition, the mass fraction of $\mathrm{SiC}$ in the SiCNTs is about $96.2 \mathrm{wt} \%$, which suggests that $3.8 \mathrm{wt} \%$ of the CNTs in the SiCNTs that are coated by SiC cannot be consumed by the silicon vapor.

As presented in Fig. 3(a), the acid-purified CNTs display diameters of 60-100 nm, a smooth surface, and a crooked morphology. Comparing the morphologies of the acid-purified CNTs and the C@SiCNTs (Fig. 3(b)), it is interesting to note that the 1-D nanotube structures are still maintained. It indicates that CNTs with suitable acid-purification maintain their nanotube structures during ultrahigh-temperature sintering. In addition, the surfaces of C@SiCNTs are rougher than those of CNTs, because of the coating of $\mathrm{SiC}$ on the surfaces of CNTs. Furthermore, the lengths of the C@SiCNTs and SiCNTs nanotubes decrease slightly, compared with that of the CNTs. No SiC nanowires are observed in the C@SiCNTs and SiCNTs. On the other hand, the reference $\mathrm{SiC}$ sample consists of nanorods and nanoparticles (Fig. 3(d)).

A perfect heterojunction interface with robust intrinsic contact in the C@SiCNTs was examined by using TEM and HRTEM. As presented in Fig. 4(a), the C@SiCNTs show a nanotube constructure with a rough surface, which is consistent 


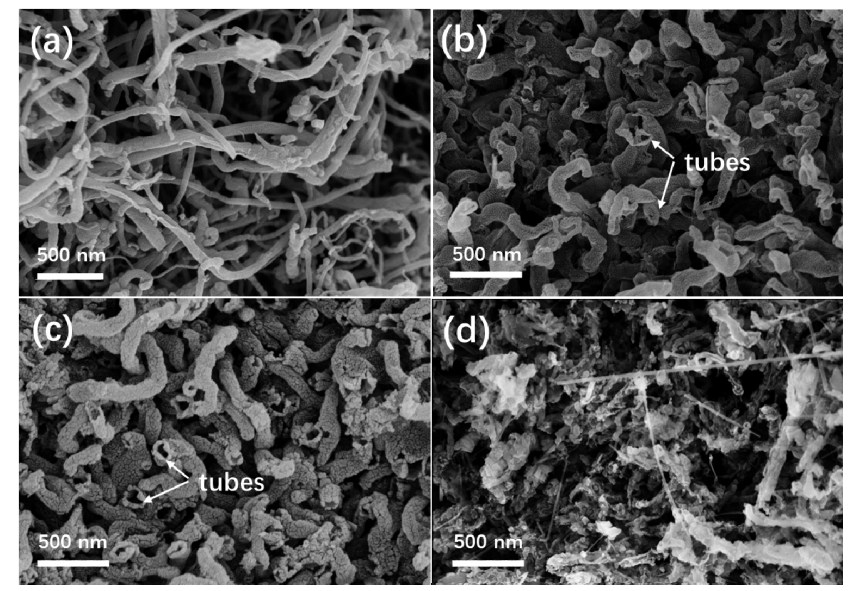

Fig. 3. SEM images of acid-purified CNTs (a), C@SiCNTs (b), SiCNTs (c) and referenced $\mathrm{SiC}(\mathrm{d})$, respectively.

with the SEM image (Fig. 3(b)), as discussed previously. For further investigation, the distributions of carbon and silicon elements are uniform, and the shapes are the same as the morphology of the C@SiCNTs. Compared to that of elemental carbon, the distribution shape of Si element is shrinked, which indicates that the SiC coating on the CNTs have formed a coaxial core-shell nanotube structure. This is further confirmed from the HRTEM image (Fig. 4(b)), in which the C@SiCNTs show two crystal lattice spacings of ca. 0.25 and $0.34 \mathrm{~nm}$, which are indexed to the (111) planes of $\beta$-SiC and the (002) planes of CNTs, respectively. Obviously, the SiC (111) planes and the CNT (002) planes connect together to form an excellent heterojunction with intrinsic atomic contact (inset in Fig. 4(b)). In addition, the HRTEM image shows that the (002) planes of CNTs are covered by the (111) planes of $\mathrm{SiC}$, which suggests the formation of a coaxial core-shell nanotube structure. As a result, rapid electron transfer from $\mathrm{SiC}$ to CNTs and electron-hole separation on the $\mathrm{SiC}$ shell will be realized, which is significant for improving the $\mathrm{PC}_{2}$ evolution.

\subsection{Optical properties and photoelectricities of the photocatalysts}

The UV-vis diffuse reflectance spectra of the samples were

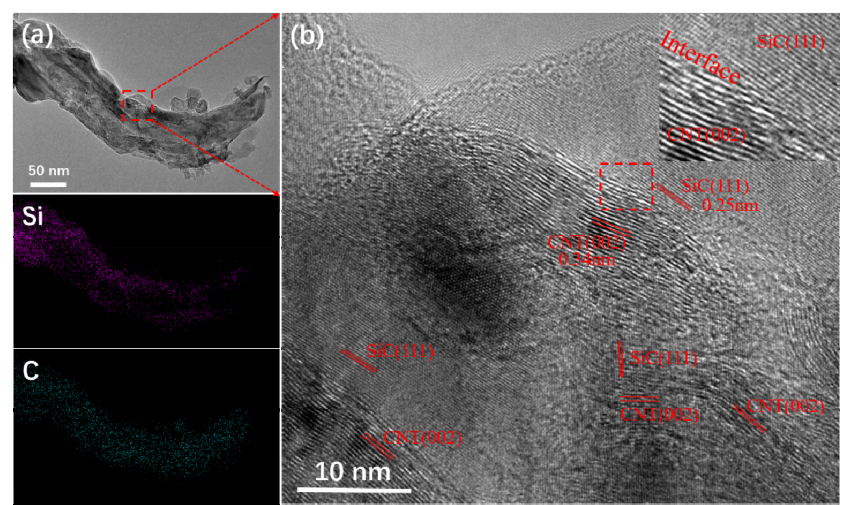

Fig. 4. TEM (a) and HRTEM (b) images of C@SiCNTs and the corresponding elemental Si and C mapping. recorded by using a spectrophotometer. As shown in Fig. 5(a), it is clear that the three specimens exhibit an absorption band in the range $200-800 \mathrm{~nm}$. Furthermore, it is also seen that the absorption band of the C@SiCNTs nanocomposites is stronger than those of the SiCNTs and the reference $\mathrm{SiC}$, which indicates better light response in the case of the C@SiCNTs, which is beneficial for the improvement of the PC activity. In addition, the band gap energies $\left(E_{\mathrm{g}}\right)$ of the $\mathrm{SiC}$ hybrids were calculated by the Kubelka-Munk method based on the tangent lines of $(\alpha h v)^{1 / 2}$ versus $h v$ plots, where $h v$ is the photon energy and $\alpha$ is the absorption coefficient [62]. As shown in Fig. 5(b), the $E_{\mathrm{g}}$ values of the C@SiCNTs, SiCNTs, and reference SiC are estimated to be $2.42,2.64$, and $2.72 \mathrm{eV}$, respectively. Obviously, the CNTs are incorporated into the $\mathrm{SiC}$ nanotubes, thus playing a powerful role in reducing the $E_{\mathrm{g}}$ of bulk $\mathrm{SiC}$ through a chemical interaction between $\mathrm{SiC}$ and CNTs. This phenomenon is similar to the result obtained in the case of ZnO-CNT composite materials [63]. In conclusion, narrowing the $E_{\mathrm{g}}$ is beneficial for improving the PC activity.

The photogenerated carrier transition behaviors of the samples were further investigated based on the PL spectra. In general, a lower PL signal strength indicates better charge capture and more efficient transport [64,65]. As shown in Fig. 5(c), the reference $\mathrm{SiC}$ reveals a strong emission peak at $468 \mathrm{~nm}$. Simultaneously, a clear fluorescence decay is seen for the C@SiCNTs sample, which indicates efficient charge separation between SiC and CNTs in the C@SiCNTs. Particularly, the emission peak intensity of the SiCNTs is lower than that of the reference $\mathrm{SiC}$, because the 1-D nanotube structures permit efficient electron transfer [66]. These results suggest that coating $\mathrm{SiC}$ onto the surfaces of CNTs and 1-D nanotubes can distinctly promote the separation and transfer of the photogenerated charge carriers.

The transient photocurrent responses of the three samples were measured for several simulated sunlight (AM 1.5) on-off cycles to demonstrate the enhanced separation of the photogenerated charge carriers. The C@SiCNTs exhibit a higher photocurrent density than the reference SiC (Fig. 5(d)), which
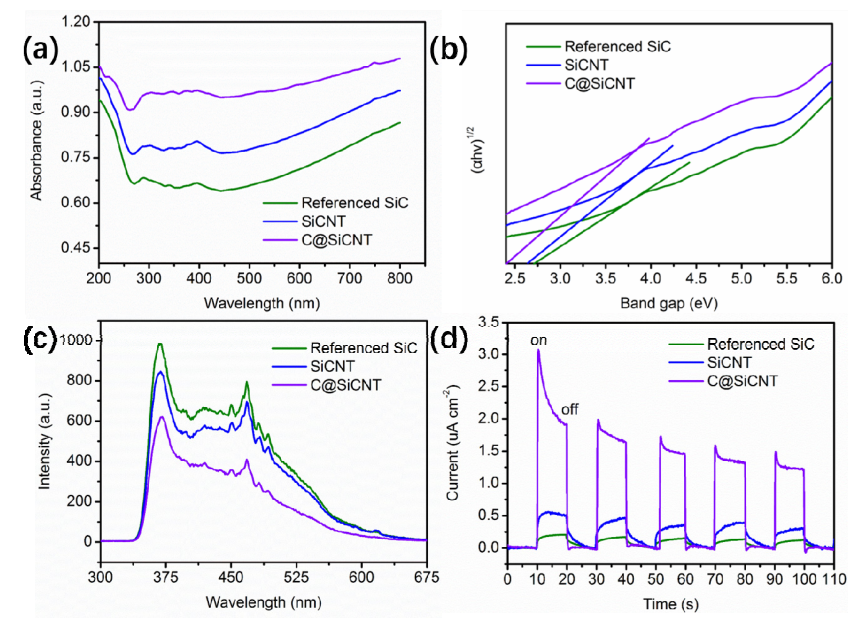

Fig. 5. UV-visible absorption spectra (a), Tauc plots (b), photoluminescence spectra (c) and transient photocurrent responses curves (d) of C@SiCNTs, SiCNTs and referenced SiC. 
indicates efficient charge separation after the hybridization of SiC with CNTs. Therefore, more electrons can be photoexcited and used to yield $\mathrm{H}_{2}$. In detail, the photocurrent density of the C@SiCNTs (about $1.3 \mu \mathrm{A} \mathrm{cm}^{-2}$ ) is 8.7 and 3.7 times higher than those of the reference $\mathrm{SiC}$ (about $0.15 \mu \mathrm{A} \mathrm{cm}^{-2}$ ) and the SiCNTs (about $0.35 \mu \mathrm{A} \mathrm{cm}^{-2}$ ), respectively. Understandably, the higher the photocurrent, the greater is the number of photogenerated electrons that can be transferred from the collected product to the counter electrode when a bias is applied [67]. Fluorescence lifetime measurements were carried out to reveal the separation of the photogenerated charge carriers, As seen in the transient PL spectrum (Fig. 6), the C@SiCNTs exhibit a slower exponential decay, with an average lifetime of $6.66 \mathrm{~ns}$, which is 2.46 and 1.42 times longer than those of the reference SiC $(2.70$ ns) and the SiCNTs (4.69 ns), respectively. The increased exciton lifetime of the C@SiCNTs suggests that the photocarrier is more likely to be involved in surface redox reactions, which is conducive to improving the PC performance.

\subsection{PC activities of the photocatalysts}

The PC $\mathrm{H}_{2}$ evolutions of the C@SiCNTs, SiCNTs, and reference $\mathrm{SiC}$ were measured under simulated sunlight irradiation (AM 1.5) in an aqueous $\mathrm{Na}_{2} \mathrm{~S}$ solution $\left(0.10 \mathrm{~mol} \mathrm{~L}^{-1}\right)$. The total amount of $\mathrm{H}_{2}$ evolved increases linearly with the irradiation time during the PC reactions over all the samples (Fig. 7(a)), which suggests that all the samples display good photostability under simulated sunlight irradiation. The total $\mathrm{H}_{2}$ productions after $5 \mathrm{~h}$ of irradiation for the C@SiCNTs, SiCNTs, and reference SiC are 592.6, 302.8, and $105.3 \mu \mathrm{mol} \mathrm{g}{ }^{-1}$, respectively.

The average $\mathrm{H}_{2}$ evolution rates over the three samples after $5 \mathrm{~h}$ of irradiation were estimated, and the values are displayed in Fig. 7(b). The $\mathrm{H}_{2}$ production rate of the C@SiCNTs $(118.5$ $\left.\mu \mathrm{mol} \mathrm{g}-1 \mathrm{~h}^{-1}\right)$ is about 5.62 and 1.95 times those of the reference SiC $\left(21.1 \mu \mathrm{mol} \mathrm{g}^{-1} \mathrm{~h}^{-1}\right)$ and the SiCNTs $\left(60.6 \mu \mathrm{mol} \mathrm{g}^{-1} \mathrm{~h}^{-1}\right)$ under simulated sunlight irradiation, respectively. A summary of the previously reported $\mathrm{SiC} /$ carbon-based photocatalysts is presented in Table 2. Even though the activity obtained here (118.5 $\mu \mathrm{mol} \mathrm{g}^{-1} \mathrm{~h}^{-1}$ ) is lower than those of graphene-covered $\mathrm{SiC} / \mathrm{Pt}$ [68], SiC-covered graphene [55], and $\mathrm{SiC} /$ carbon nanofibers[61], it is better than those of other $\mathrm{SiC} /$ carbon-based photocatalysts such as GO/SiC [53], SiC-graphene [52], and MWCNTs/SiC nanowires, which suggests an excellent synergetic effect between the CNT cores and the SiC shells.

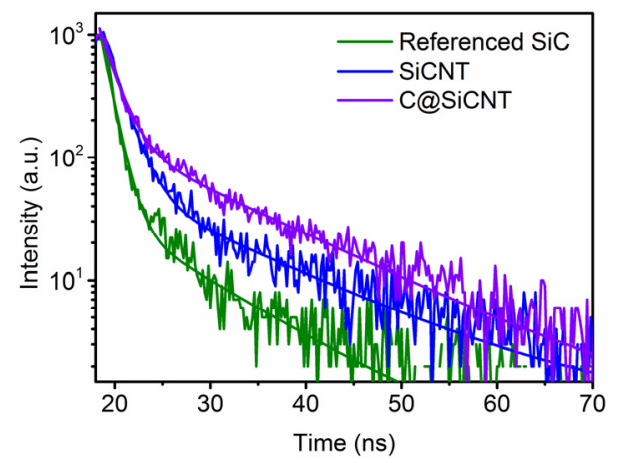

Fig. 6. Transient PL spectra of C@SiCNTs, SiCNTs and referenced SiC.
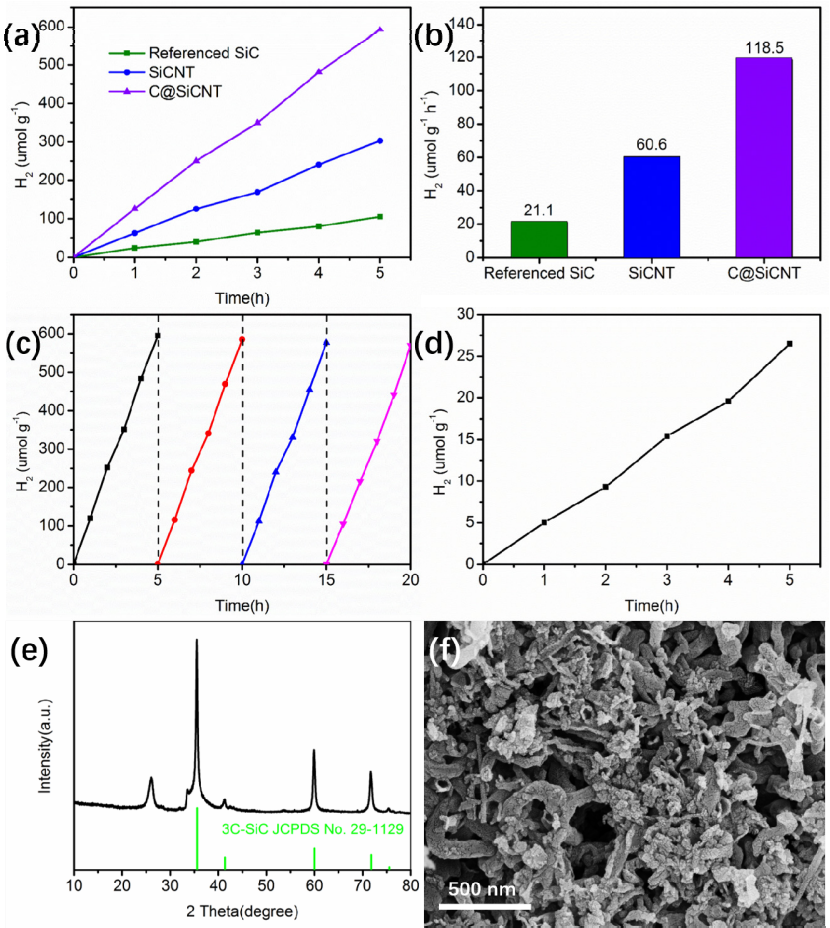

Fig. 7. The total amount of $\mathrm{H}_{2}$ produced by the C@SiCNTs, SiCNTs and referenced $\mathrm{SiC}$ photocatalysis under AM 1.5 simulated sunlight irradiation (a) and their corresponding average hydrogen production rates (b) the repeated runs of PC $\mathrm{H}_{2}$ evolution using the C@SiCNT heterostructures(c), the total amount of $\mathrm{H}_{2}$ produced for the C@SiCNTs in pure water without any sacrificial reagent under AM 1.5 simulated sunlight irradiation (d), the XRD patterns (e) and SEM image (f) of the C@SiCNTs after cyclic experiments.

In addition, the stability of the C@SiCNTs in PC $\mathrm{H}_{2}$ evolution was investigated by cyclic experiments. As displayed in Fig. 7 (c), after four repeated runs, no remarkable decay in the $\mathrm{H}_{2}$ evolution is observed after the PC reaction for $20 \mathrm{~h}$ under simulated sunlight irradiation. It is further demonstrated that the C@SiCNTs photocatalyst also exhibits excellent stability during PC $\mathrm{H}_{2}$ production. To further confirm the good stability of the C@SiCNTs photocatalyst, the structural morphology of the C@SiCNTs was characterized after the cyclic experiments. The XRD pattern and SEM image of the C@SiCNTs obtained after the cyclic experiments are shown in Fig. 7(e) and Fig. 7(f), respectively. As can be seen, there is no obvious change in the structure and morphology of the C@SiCNTs after the cyclic experiments.

In order to clarify that the photogenerated holes were consumed by $\mathrm{Na}_{2} \mathrm{~S}$, the PC $\mathrm{H}_{2}$ evolution over the C@SiCNTs was investigated in pure under simulated sunlight irradiation. The total amount (Fig. 7(d)) of $\mathrm{H}_{2}$ produced increases linearly. The average $\mathrm{H}_{2}$ evolution rate over the C@SiCNTs after $5 \mathrm{~h}$ irradiation is $5.3 \mu \mathrm{mol} \mathrm{g}^{-1} \mathrm{~h}^{-1}$. The results confirmed that the $\mathrm{H}_{2}$ production rate of C@SiCNTs in a $\mathrm{Na}_{2} \mathrm{~S}$ solution is higher than that in pure water under simulated sunlight irradiation, since the recombination of the photogenerated charge carriers is remarkably suppressed.

\subsection{Discussion of the mechanism}


Table 2

Summary of the $\mathrm{PC} \mathrm{H}_{2}$ evolutions on $\mathrm{SiC}$ /carbon-based photocatalysts.

\begin{tabular}{|c|c|c|c|c|c|}
\hline Photocatalyst & Mass (mg) & Sacrificial reagent & Power (Xe lamp), wavelength & Activity $\left(\mu \mathrm{mol} \mathrm{g}{ }^{-1} \mathrm{~h}^{-1}\right)$ & Ref. (year) \\
\hline $\mathrm{GO} / \mathrm{SiC}$ & 100 & $0.3 \mathrm{~mol} / \mathrm{L} \mathrm{KI}$ & $300 \mathrm{~W}, \lambda \geq 400 \mathrm{~nm}$ & 41.3 & $(2013)[53]$ \\
\hline SiC-graphene & 100 & Pure water & $300 \mathrm{~W}, \lambda>420 \mathrm{~nm}$ & 3.91 & $(2013)[52]$ \\
\hline Graphene-covered SiC/Pt & 100 & $0.1 \mathrm{~mol} / \mathrm{L} \mathrm{Na}_{2} \mathrm{~S}$ and $\mathrm{Na}_{2} \mathrm{SO}_{3}$ & $300 \mathrm{~W}, \mathrm{AM} 1.5 \mathrm{G}$ & 300 & $(2015)[68]$ \\
\hline SiC-covered graphene & 50 & $0.1 \mathrm{~mol} / \mathrm{L} \mathrm{Na}_{2} \mathrm{~S}$ & $300 \mathrm{~W}, \lambda \geq 420 \mathrm{~nm}$ & 428.4 & $(2015)[55]$ \\
\hline MWCNTs/SiC nanowires & 50 & $0.1 \mathrm{~mol} / \mathrm{L} \mathrm{Na} 2 \mathrm{~S}$ & $300 \mathrm{~W}, \lambda \geq 420 \mathrm{~nm}$ & 108 & $(2015)[56]$ \\
\hline SiC/carbon nanofibers & 25 & $20 \%$ methanol & $300 \mathrm{~W}, \lambda \geq 450 \mathrm{~nm}$ & 180.2 & $(2017)[61]$ \\
\hline C@SiCNT & 15 & $0.1 \mathrm{~mol} / \mathrm{L} \mathrm{Na}_{2} \mathrm{~S}$ & $300 \mathrm{~W}, \mathrm{AM} 1.5 \mathrm{G}$ & 118.5 & This work \\
\hline C@SiCNT & 15 & Pure water & $300 \mathrm{~W}, \mathrm{AM} 1.5 \mathrm{G}$ & 5.3 & This work \\
\hline
\end{tabular}

In view of the above analysis of the hybrids, the enhanced PC performance of the C@SiCNTs can be attributed to the 1-D coaxial core-shell nanoheterostructures and to the Schottky junction formed between CNTs and SiC, which results in efficient intrinsic interfacial charge transfer. The Schottky-type junction of C@SiCNTs improves the PC activity in three ways: (1) the 1-D coaxial core-shell nanotube structures exhibit excellent performances such as rapid electron transport and enhanced light absorption and scattering; (2) CNTs act as photosensitizers by enhancing the absorption of light. This is confirmed by UV-vis spectroscopy (Fig. 5(a)), which reveals that the absorption band of C@SiCNTs is stronger than those of SiCNTs and the reference SiC [69]; (3) a robust Schottky junction is formed between CNTs and the semiconductor by in situ growth of SiC nanoshells on the CNTs [70]. Such a junction decreases the barrier for charge transfer and thus suppresses the electron-hole recombination.

The flat band ( $\mathrm{fb}$ ) potentials of the SiC nanostructures were estimated based on the Mott-Schottky plots by using Eq. (4). The surface carrier density was determined according to Eq. (5).

$$
\begin{gathered}
\frac{1}{\mathrm{C}^{2}}=\left[\frac{2}{\mathrm{e}_{0} \varepsilon \cdot \varepsilon_{0} \mathrm{~N}_{\mathrm{d}} \mathrm{A}^{2}}\right]\left[\mathrm{E}-\mathrm{E}_{\mathrm{fb}}-\frac{\mathrm{KT}}{\mathrm{e}}\right] \\
\mathrm{N}_{\mathrm{d}}=2 \times\left(\varepsilon \cdot \varepsilon_{0} \cdot \mathrm{e}_{0}\right)^{-1} \times\left[\mathrm{d}\left(1 / \mathrm{C}^{2}\right) / \mathrm{dE}\right]^{-1}
\end{gathered}
$$

where $\mathrm{C}$ is the space charge layer capacitance, $\mathrm{N}_{\mathrm{d}}$ stands for electron donor density, eo stands for electron charge, $E$ denotes the applied potential, and $\varepsilon$ and $\varepsilon_{0}$ represent the permittivity of the material and the permittivity of vacuum, respectively. According to a previous report, the $\varepsilon$ value of $\beta$-SiC is 6.9 and the $\varepsilon_{0}$ value is $8.85 \times 10^{-12} \mathrm{~F} \mathrm{~m}^{-1}$ [71]. $V_{\mathrm{fb}}$ is the flat band potential, which is calculated by extrapolating the fitted line to $\mathrm{C}^{-2}=0$. The positive tangent slopes imply that the three photocatalysts are n-type semiconductors (as displayed in Fig. 8(a)). The estimated $\mathrm{V}_{\mathrm{fb}}$ for the C@SiCNTs, SiCNTs, and reference SiC are $-0.102,0.002$, and $0.017 \mathrm{~V}$ (vs RHE), respectively. Obviously, the $V_{\mathrm{fb}}$ of the C@SiCNTs exhibits a positive shift, compared to that of the reference $\mathrm{SiC}$, since the Fermi level of $\mathrm{SiC}$, which is below the conduction band, is more negative than the Fermi level of CNTs. The electrons of SiC are transferred to CNTs across the interface between $\mathrm{SiC}$ and CNTs. These electron movements result in band bending at the interface between $\mathrm{SiC}$ and CNTs, and consequently, generate an interfacial electric field. In addition, the C@SiCNTs exhibit a much smaller positive slope than the reference $\mathrm{SiC}$, which suggests a larger electron density for the C@SiCNT photocatalyst. The $\mathrm{N}_{\mathrm{d}}$ are $1.18 \times 10^{22}$,
$9.67 \times 10^{21}$, and $6.69 \times 10^{21}$ for the C@SiCNTs, SiCNTs, and reference $\mathrm{SiC}$, respectively. The aforementioned photoelectrochemical measurement results are in accordance with the charge densities of the three samples.

The charge transfer kinetics of the C@SiCNTs, SiCNTs, and reference $\mathrm{SiC}$ were further investigated based on the electrochemical impedance spectra that were obtained under illumination at an ac amplitude of $5 \mathrm{mV}$ in the frequency range 0.01-105 Hz. A smaller radius of the semicircle in the EIS curve indicates a better ability to transport charges [72]. Obviously, the radius of the semicircle of the C@SiCNTs is smaller than those of the SiCNTs and reference SiC (as seen in Fig. 8(b)), which suggests that the coaxial core-shell nanotube heterostructures can effectively reduce the interfacial charge transfer resistance and enhance the separation efficiency of the photogenerated charge carriers.

By using a Xe lamp equipped with pieces of band-pass filters, the $\mathrm{H}_{2}$ generation properties of the C@SiCNTs, SiCNTs, and reference SiC were further measured under $420 \mathrm{~nm}$ monochromatic light irradiation. The average rates of $\mathrm{PC}_{2}$ generation over the C@SiCNTs, SiCNTs, and reference SiC were 53.5, 24.3, and $6.3 \mu \mathrm{mol} \mathrm{g} \mathrm{g}^{-1} \mathrm{~h}^{-1}$, respectively (Fig. 8(c)). The corresponding AQEs of the C@SiCNTs, SiCNTs, and reference SiC under $420 \mathrm{~nm}$ visible light irradiation reached $0.081 \%$, $0.037 \%$, and $0.01 \%$, respectively (Fig. $8(d)$ ). The AQE of the C@SiCNTs is much higher than that of the reference SiC, which further indicates that C@SiCNTs can deliver more photoelec-
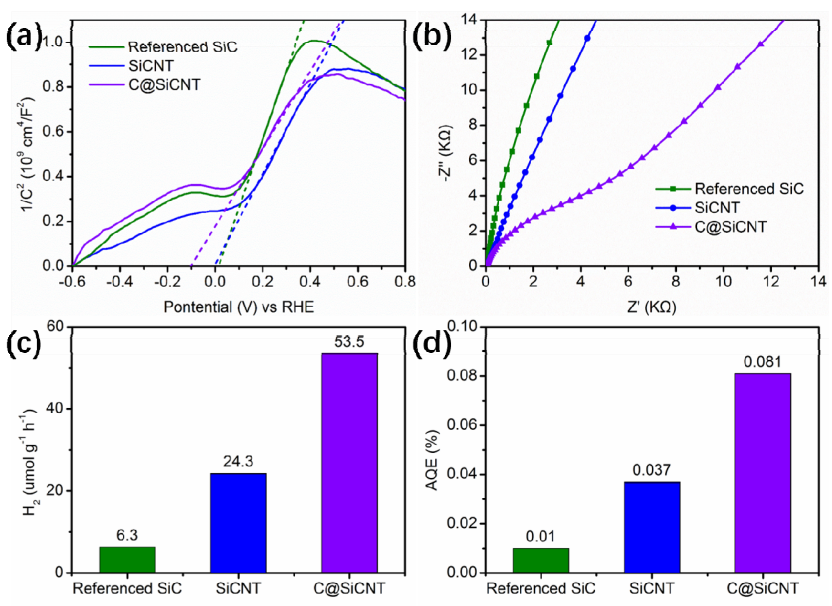

Fig. 8. Mott-Schottky (MS) plots (a), electrochemical impedance spectroscopy (EIS) Nyquist plots (b), the average rates of the $\mathrm{PC} \mathrm{H}_{2}$ generation (c) and the AQE for the C@SiCNTs, SiCNTs and referenced SiC under $420 \mathrm{~nm}$ monochromatic light irradiation. 


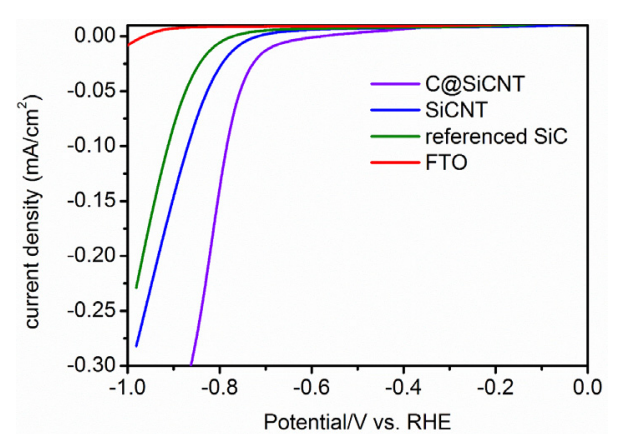

Fig. 9. Polarization curves of C@SiCNTs, SiCNTs and referenced SiC.

trons for the $\mathrm{H}_{2}$ reduction reaction.

The polarization curves for the electrocatalytic $\mathrm{H}_{2}$ evolutions over the C@SiCNTs, SiCNTs, and reference SiC were obtained at $5 \mathrm{mV} \mathrm{s}^{-1}$ scan rate from $0 \mathrm{~V}$ to $-1.0 \mathrm{~V}$ vs RHE. As shown in Fig. 9, the onset potentials for electrocatalytic $\mathrm{H}_{2}$ evolutions over the C@SiCNTs, SiCNTs, and reference SiC are about $-0.45,-0.69$, and $-0.78 \mathrm{~V}$ (vs RHE), respectively. The C@SiCNTs exhibit reduced onset overpotentials, which suggest that the formation of the heterojunction between SiC and CNTs improves the catalytic activity. All the SiC samples exhibit much lower overpotentials than the bare FTO, which indicates that $\mathrm{SiC}$ displays a higher catalytic activity [47].

Illustrations of the electron-hole transfer in C@SiCNTs and the PC $\mathrm{H}_{2}$ production mechanism over C@SiCNTs photocatalysts are shown in Scheme 2. The electrons in the VB of SiC can be excited to the $\mathrm{CB}$ of SiC under simulated sunlight irradiation. The photogenerated electrons from the excited $\mathrm{SiC}$ can be transferred to the CNTs, because CNTs display a higher electrical conductivity and a more positive Fermi level than $\mathrm{SiC}$ (based on the work functions of SiC (4.4 eV) [73] and CNTs (4.8 $\mathrm{eV}$ ) [74]. Furthermore, the 1-D coaxial core-shell nanotube structures consisting of CNT cores and SiC shells offer abundant channels for charge transfer, which suppresses the recombination of the photogenerated electron-hole pairs. CNTs function as an electron donor to accept the photogenerated electrons from the host $\mathrm{SiC}$ to produce $\mathrm{H}_{2}$. Meanwhile, the holes
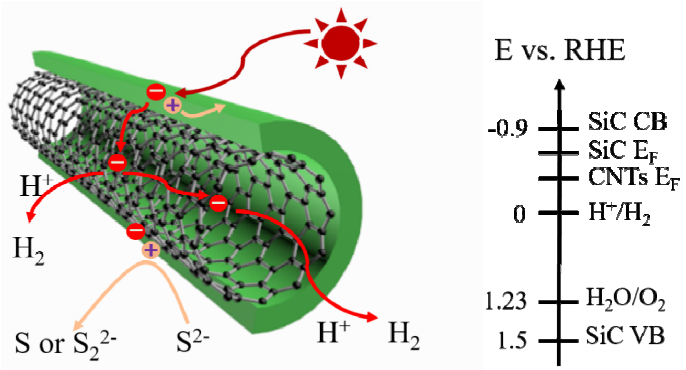

Scheme 2. Schematic mechanism of the charge transfer behavior in the C@SiCNTs and a possible PC $\mathrm{H}_{2}$ evolution mechanism over C@SiCNT photocatalysts.

can be consumed by the sacrificial reagent $\left(\mathrm{Na}_{2} \mathrm{~S}\right)$ to regenerate the ground-state $\mathrm{SiC}$. As a result, a significantly enhanced reaction activity and stable $\mathrm{PC} \mathrm{H}_{2}$ evolution can be achieved over the 1-D coaxial core-shell CNTs@SiC nanotube photocatalysts.

\section{Conclusions}

We demonstrated that the PC performance of the SiC/CNTs hybrid can be effectively improved through rational engineering of the morphology and interfaces of the $\mathrm{SiC}$ active layer. C@SiCNTs with a coaxial core-shell nanotube structure were synthesized by an in situ vapor-solid chemical reaction between CNTs and silicon vapor. The obtained C@SiCNTs exhibited a high photoactivity and stability in water splitting. The enhanced PC activity of the CNTs/SiC hybrids is attributed to the synergistic effects between $\mathrm{SiC}$ and CNTs, including the 1-D core-shell nanotube heterostructure, enhanced light absorption, as well as the formation of tight Schottky-type heterojunctions between CNTs and $\mathrm{SiC}$, which promote charge separation at the interfaces of nanoheterostructures.

\section{References}

[1] X. Li, J. Yu, M. Jaroniec, X. Chen, Chem. Rev., 2019, 119,

\section{Graphical Abstract}

Chin. J. Catal., 2020, 41: 62-71 doi: S1872-2067(19)63421-2

Carbon nanotube@silicon carbide coaxial heterojunction nanotubes as metal-free photocatalysts for enhanced hydrogen evolution

Xunfu Zhou, Qiongzhi Gao, Siyuan Yang *, Yueping Fang * South China Agricultural University

One-dimensional carbon@silicon carbide coaxial heterojunction nanotubes with a perfect heterointerface and an outstanding photocatalytic activity were successfully synthesized via in situ growth of SiC coatings on CNTs that involves a vapor-solid reaction between silicon vapor and CNTs.

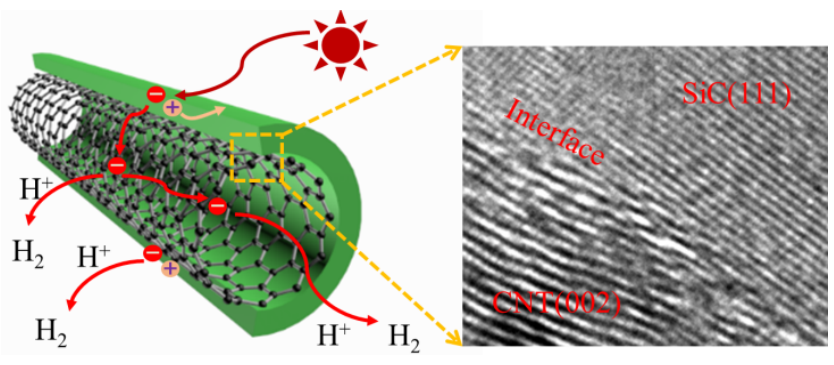


3962-4179.

[2] J. A. Turner, Science, 2004, 305, 972-974.

[3] X. Li, R. Shen, S. Ma, X. Chen, J. Xie, Appl. Surf. Sci., 2018, 430, 53-107.

[4] G. Xie, K. Zhang, B. Guo, Q. Liu, L. Fang, J. R. Gong, Adv. Mater., 2013, 25, 3820-3839.

[5] W. Wang, D. Xu, B. Cheng, J. Yu, C. Jiang, J. Mater. Chem. A, 2017, 5, 5020-5029.

[6] Q. Xu, B. Cheng, J. Yu, G. Liu, Carbon, 2017, 118, 241-249.

[7] B. Liu, X. Liu, L. Li, J. Li, C. Li, Y. Gong, L. Niu, X. Zhao, C. Q. Sun, Chin. J. Catal., 2018, 39, 1901-1909.

[8] Q. Li, B. Guo, J. Yu, J. Ran, B. Zhang, H. Yan, J. R. Gong, J. Am. Chem. Soc., 2011, 133, 10878-10884.

[9] J. Zhang, J. Yu, M. Jaroniec, J. R. Gong, Nano Lett., 2012, 12, 4584-4589.

[10] K. Zhang, Q. Liu, H. Wang, R. Zhang, C. Wu, J. R. Gong, Small, 2013, 9, 2452-2459.

[11] J. Cai, W. Liu, Z. Li, Appl. Surf. Sci., 2015, 358, 146-151.

[12] C. A. Bignozzi, S. Caramori, V. Cristino, R. Argazzi, L. Meda, A. Tacca, Chem. Soc. Rev., 2013, 42, 2228-2246.

[13] G.-J. Lee, J. J. Wu, Powder Technol., 2017, 318, 8-22.

[14] Q. Hao, S. Hao, X. Niu, X. Li, D. Chen, H. Ding, Chin. J. Catal., 2017, $38,278-286$.

[15] S. Ma, X. Xu, J. Xie, X. Li, Chin. J. Catal., 2017, 38, 1970-1980.

[16] Z. Mo, H. Xu, Z. Chen, X. She, Y. Song, P. Yan, Y. Xu, Y. Lei, S. Yuan, H. Li, Chin. J. Catal., 2018, 39, 760-770.

[17] H. He, L. Huang, Z. Zhong, S. Tan, Appl. Surf. Sci., 2018, 441, 285-294.

[18] Y. Ding, Y. Gao, Z. Li, Appl. Surf. Sci., 2018, 462, 255-262.

[19] G. Xie, K. Zhang, H. Fang, B. Guo, R. Wang, H. Yan, L. Fang, J. R. Gong, Chem. Asian J., 2013, 8, 2395-2400.

[20] Q. Li, H. Meng, P. Zhou, Y. Zheng, J. Wang, J. Yu, J. Gong, ACS Catal., 2013, 3, 882-889.

[21] X. Li, J. Yu, J. Low, Y. Fang, J. Xiao, X. Chen, J. Mater. Chem. A, 2015, 3, 2485-2534.

[22] S. Cao, J. Yu, J Photochem. Photobio C, 2016, 27, 72-99.

[23] Q. Xu, C. Jiang, B. Cheng, J. Yu, Dalton Trans., 2017, 46,10611-10619.

[24] K. Woan, G. Pyrgiotakis, W. Sigmund, Adv. Mater., 2009, 21, 2233-2239.

[25] A. Hu, S. Liu, W. Lin, RSC Adv., 2012, 2, 2576-2580.

[26] S. Hoang, S. P. Berglund, N. T. Hahn, A. J. Bard, C. B. Mullins, J. Am. Chem. Soc., 2012, 134, 3659-3662.

[27] Y. J. Hwang, A. Boukai, P. Yang, Nano Lett., 2009, 9, 410-415.

[28] C. G. Silva, J. L. Faria, Appl. Catal. B, 2010, 101, 81-89.

[29] Y. Yu, J. C. Yu, C.-Y. Chan, Y.-K. Che, J.-C. Zhao, L. Ding, W.-K. Ge, P.-K. Wong, Appl. Catal. B, 2005, 61, 1-11.

[30] N. Bouazza, M. Ouzzine, M. A. Lillo-Ródenas, D. Eder, A. Linares-Solano, Appl. Catal. B, 2009, 92, 377-383.

[31] Y.-J. Xu, Y. Zhuang, X. Fu, J. Phys. Chem. C, 2010, 114, 2669-2676.

[32] Z. Li, B. Gao, G. Z. Chen, R. Mokaya, S. Sotiropoulos, G. Li Puma, Appl. Catal. B, 2011, 110, 50-57.

[33] K. Dai, G. Dawson, S. Yang, Z. Chen, L. Lu, Chem. Eng. J., 2012, 191, 571-578.

[34] S.-A. Feng, J.-H. Zhao, Z.-P. Zhu, New Carbon Mater., 2008, 23, 228-234.

[35] Y. Hu, Y. Liu, H. Qian, Z. Li, J. F. Chen, Langmuir, 2010, 26, 18570-18575.

[36] L. Tian, L. Ye, J. Liu, L. Zan, Catal. Commun., 2012, 17, 99-103.

[37] Y. Xu, H. Xu, L. Wang, J. Yan, H. Li, Y. Song, L. Huang, G. Cai, Dalton Trans., 2013, 42, 7604-7613.

[38] M. Steenackers, I. D. Sharp, K. Larsson, N. A. Hutter, M. Stutzmann,
R. Jordan, Chem. Mater., 2010, 22, 272-278.

[39] Y. Li, Z. Yu, J. Meng, Y. Li, Int. J. Hydrogen Energy, 2013, 38, 3898-3904.

[40] W. Zhou, L. Yan, Y. Wang, Y. Zhang, Appl. Phys. Lett., 2006, 89, 013105/1-013105/3.

[41] D. Beke, K. Horváth, K. Kamarás, A. Gali, Langmuir, 2017, 33, 14263-14268.

[42] J.-Y. Hao, Y.-Y. Wang, X.-L. Tong, G.-Q. Jin, X.-Y. Guo, Catal. Today, 2013, 212, 220-224.

[43] M. Wang, J. Chen, X. Liao, Z. Liu, J. Zhang, L. Gao, Y. Li, Int. J. Hydrogen Energy, 2014, 39, 14581-14587.

[44] Y. Wang, L. Zhang, X. Zhang, Z. Zhang, Y. Tong, F. Li, J. C. S. Wu, X. Wang, Appl. Catal. B, 2017, 206, 158-167.

[45] C. B. D. Marien, M. Le Pivert, A. Azaïs, I. C. M’Bra, P. Drogui, A. Dirany, D. Robert, J. Hazard Mater., 2018, 164-171.

[46] J. Zhang, X. L. Wu, L. Z. Liu, L. Yang, Z. X. Gan, P. K. Chu, AIP Adv., 2015, 5, 037120/1-037120/7.

[47] X. Guo, X. Tong, Y. Wang, C. Chen, G. Jin, X.-Y. Guo, J. Mater. Chem. A, 2013, 1, 4657-4661.

[48] X. Zhou, Y. Liu, X. Li, Q. Gao, X. Liu, Y. Fang, Chem. Commun., 2014, 50, 1070-1073.

[49] X. Liao, J. Chen, M. Wang, Z. Liu, L. Ding, Y. Li, J. Alloys Compd., 2016, 658, 642-648.

[50] Y. Peng, Z. Guo, J. Yang, D. Wang, W. Yuan, J. Mater. Chem. A, 2014, 2, 6296-6300.

[51] D. Wang, W. Wang, Q. Wang, Z. Guo, W. Yuan, Mater. Lett., 2017, 201, 114-117.

[52] Y. Wang, X. Guo, L. Dong, G. Jin, Y. Wang, X.-Y. Guo, Int. J. Hydrogen Energy, 2013, 38, 12733-12738.

[53] J. Yang, X. Zeng, L. Chen, W. Yuan, Appl. Phys. Lett., 2013, 102, 083101/1-083101/4.

[54] Y. Nariki, Y. Inoue, K. Tanaka, J. Mater. Sci., 1990, 25, 3101-3104.

[55] X. Zhou, Q. Gao, X. Li, Y. Liu, S. Zhang, Y. Fang, J. Li, J. Mater. Chem. A, 2015, 3, 10999-11005.

[56] X. Zhou, X. Li, Q. Gao, J. Yuan, J. Wen, Y. Fang, W. Liu, S. Zhang, Y. Liu, Catal. Sci. Technol., 2015, 5, 2798-2806.

[57] J. Song, H. Zhao, R. Sun, X. Li, D. Sun, Energy Environ. Sci., 2017, 10, 225-235.

[58] R. Wu, K. Zhou, C. Y. Yue, J. Wei, Y. Pan, Prog. Mater. Sci., 2015, 72, 1-60.

[59] F. O. Saeva, Pure Appl. Chem., 1974, 38, 25-36.

[60] J. Xu, Y. Wang, Y. Zhu, Langmuir, 2013, 29, 10566-10572.

[61] B. Wang, Y. Wang, Y. Lei, N. Wu, Y. Gou, C. Han, S. Xie, D. Fang, Nano Res., 2016, 9, 886-898.

[62] J. Wen, J. Xie, H. Zhang, A. Zhang, Y. Liu, X. Chen, X. Li, ACS Appl. Mater. Interfaces, 2017, 9, 14031-14042.

[63] T. Lv, L. Pan, X. Liu, Z. Sun, Catal. Sci. Technol., 2012, 2, 2297-2301.

[64] T. Maassen, J. J. van den Berg, N. Ijbema, F. Fromm, T. Seyller, R. Yakimova, B. J. van Wees, Nano Lett., 2012, 12, 1498-1502.

[65] S. Ma, Y. Deng, J. Xie, K. He, W. Liu, X. Chen, X. Li, Appl. Catal. B, 2018, 227, 218-228.

[66] R. L. Zhou, R. Z. Zuo, L. Wang, B. H. Zhang, B. C. Pan, J. Appl. Phys., 2011, 109, 084318/1-084318/7.

[67] Q. Xiang, J. Yu, M. Jaroniec, J. Am. Chem. Soc., 2012, 134, 6575-6578.

[68] W. Lu, D. Wang, L. Guo, Y. Jia, M. Ye, J. Huang, Z. Li, Y. Peng, W. Yuan, X. Chen, Adv. Mater., 2015, 27, 7986-7991.

[69] B. Weng, S. Liu, N. Zhang, Z.-R. Tang, Y.-J. Xu, J Catal, 2014, 309, 146-155.

[70] A. S. Cherevan, P. Gebhardt, C. J. Shearer, M. Matsukawa, K. Domen, D. Eder, Energy Environ. Sci., 2014, 7, 791-796.

[71] J. Nakamura, A. Natori, Surf. Sci., 2006, 600, 4332-4336. 
[72] T. Butburee, Y. Bai, H. Wang, H. Chen, Z. Wang, G. Liu, J. Zou, P. Khemthong, G. Q. M. Lu, L. Wang, Adv. Mater., 2018, 30,1705666.
[73] K. Senthil, K. Yong, Mater. Chem. Phys., 2008, 112, 88-93.

[74] M. Shiraishi, M. Ata, MRS Proceedings, 2011, 633, A4.4.

\title{
碳纳米管@碳化硅同轴异质结纳米管非金属光催化剂产氢性能
}

\author{
周训富，高琼芝，杨思源"，方岳平 \\ 华南农业大学材料与能源学院, 广东广州 510642
}

\begin{abstract}
摘要: 近年来, 光催化裂解水产氢 $\left(\mathrm{H}_{2}\right)$ 引起了广泛的关注. 储量丰富, 环境友好的非金属无机半导体 $\beta-\mathrm{SiC}$ (立方相碳化硅) 具有适当的带隙 $\left(E_{\mathrm{g}}=2.4 \mathrm{eV}, E_{\mathrm{CB}}=-0.9 \mathrm{~V}\right)$, 是一种潜在的光催化剂. 受限于 $\mathrm{SiC}$ 光催化剂内部光生电子-空穴对的快速复 合, $\mathrm{SiC}$ 光催化剂的效率较低. 已有的关于 $\mathrm{SiC}$ 光催化剂改性的报道主要包括构建纳米 $\mathrm{SiC}$, 构建 $\mathrm{SiC}$ 异质结, 构建碳/ $\mathrm{SiC}$ 材料 杂化材料. 进一步的研究表明, $\mathrm{SiC}$ 与碳材料之间通过紧密的界面接触形成了肖特基结, 能将 $\mathrm{SiC}$ 表面的光生电子快速转移, 抑制光生电子-空穴对的快速复合, 从而提高光催化分解水产氢的活性. 另一方面, 碳纳米管(CNTs)具有良好的电子导电 性, 一维有序的管腔所形成的电子快速传导路径. 因此, 将半导体光催化剂与CNTs复合, 是一种制备先进的光催化剂的有 效策略.

本文利用 $\mathrm{Si}$ 蒸气与 CNTs之间的气-固反应, 在 CNTs 表面原位生长 $\mathrm{SiC}$ 纳米包覆层, 成功地制备了一维同轴核-壳

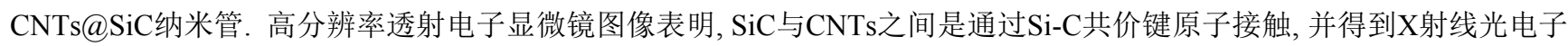

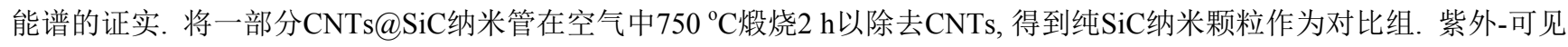
吸收光谱表明, CNTs能够促进 $\mathrm{SiC}$ 对光的吸收. 苂光发射光谱(PL), 瞬态荧光寿命测试, 瞬态光电流测试以及交流阻抗(EIS) 测试表明, CNTs能够促进 $\mathrm{SiC}$ 表面光生电子的传输与分离, 有利于提升光催化效率. 以 $0.1 \mathrm{~mol} / \mathrm{L} \mathrm{Na} \mathrm{N}_{2} \mathrm{~S}$ 溶液作为牺牲剂, 在 模拟太阳光(A.M 1.5)照射下, CNTs@SiC纳米管(不额外负载Pt等贵金属作为助剂)的产氢速率为 $118.5 \mu \mathrm{mol} \mathrm{g}^{-1} \mathrm{~h}^{-1}$, 是纯 $\mathrm{SiC}$ 纳米颗粒 $\left(21.1 \mu \mathrm{mol} \mathrm{g}^{-1} \mathrm{~h}^{-1}\right)$ 的 5.62 倍. 经过 $20 \mathrm{~h}$ 的光照测试, CNTs@SiC纳米管的光催化性能无明显衰减; X射线衍射测 试与扫描电子显微镜图像表明, CNTs@SiC纳米管的结构与形貌反应前后几乎无变化. 莫特-肖特基测试表明, CNTs的费 米能级比 $\mathrm{SiC}$ 低, 因此 $\mathrm{SiC}$ 表面的光生电子能够快速地转移到 $\mathrm{CNTs}$, 并且CNTs的良好导电性与一维有序的管腔所形成的长 的电子传导路径能够进一步地增加电子寿命, 促进光生电子参与光催化反应. 另外, 通过原子连接的同轴核-壳CNTs@SiC 纳米管提供了大量且有效的电子传输路径. 因此, 与纯 $\mathrm{SiC}$ 纳米晶等同类材料相比, 无机非金属 $\mathrm{CNTs} @ \mathrm{SiC}$ 纳米管具有更强 的光催化氢活性.
\end{abstract}

关键词: 碳化硅; 同轴核-壳纳米管; 纳米异质结; 电荷分离; 析氢

收稿日期: 2019-04-29. 接受日期: 2019-06-03. 出版日期: 2020-01-05.

*通讯联系人. 电子信箱: siyuan_yang@scau.edu.cn

通讯联系人. 电话: 13570347090; 电子信箱: ypfang@scau.edu.cn

基金来源：国家自然科学基金(21673083, 21802046); 广东省科技项目(2017A030313090, 2014A030310427).

本文的电子版全文由Elsevier出版社在ScienceDirect上出版(http://www.sciencedirect.com/science/journal/18722067). 